\title{
DORIS SALCEDO: MEMÓRIAS DA EXCLUSÃO E VIOLÊNCIA
}

\author{
Maria Luiza Calim de Carvalho Costa ${ }^{1}$
}

\begin{abstract}
The Colombian artist Doris Salcedo demonstrates, through his works, the universal vulnerability of human beings. The artist uses a concrete materiality such as furniture that is part of everyday life, and builds abstract works, sometimes unusual images, requiring the reader to excavate layers of memory and adjust his perception to decipher the poetic deviation and establish the sense. The theme is violence that humanity was and still been submitted in all corners of the world, particularly Latin America in the stories of oppression, dictatorships, civil wars, civil rights violated, etc. Her works echo the "silent scream" of the vulnerable.

Index Terms — Latin America, contemporary art, Doris Salcedo.
\end{abstract}

\section{INTRODUÇÃO}

Em nossa pesquisa intitulada "Sulear: Incursões Visuais Latino-Americanas", cujo objeto é a América Latina mestiça, híbrida e heterogenia apresentada pelos olhos sensíveis da arte, temos nos deparado com questões como por exemplo: Qual a configuração da América Latina? Como artistas latino-americanos configuram com suas obras modos de ver a América Latina? Como se imbricam o local e o global nessas obras contemporâneas?

Para esse artigo, elegemos obras da artista colombiana Doris Salcedo (Bogotá,1958- ) que traz à reflexão a vulnerabilidade do ser humano. É do campo de experiências do Terceiro Mundo, como uma artista da zona periférica, que Salcedo constrói seu discurso poético. Doris Salcedo se auto intitula uma artista política que trabalha a partir da experiência de viver em um país do Terceiro Mundo. Desse lugar onde nasceu e habita, a Colômbia, é que a artista fala.

Sua obra, apesar de partir da experiência originária da guerra vivida a décadas em seu país, apresenta uma dimensão universal ao tocar na questão da vulnerabilidade do ser humano e na violência que persiste no mundo inteiro. Para Salcedo, "a violência existe em todas as partes com diferentes matizes, mas com igual intensidade" (SALCEDO,2013, p.23).

Acho interessante conectar a violência diária em todo planeta, porque evidentemente, não é uma característica exclusiva dos países menos desenvolvidos. [...] Interessa encontrar o que é puramente humano, o que é comum a todos os homens, e colocar isso em evidência. Este aspecto comum em todo ser humano é exatamente nossa grande vulnerabilidade, somos seres finitos, portanto vulneráveis (SALCEDO,2013, p.23).

Portanto, sua obra não se limita à experiência colombiana, parte dela, mas a transcende.

A artista parte de uma materialidade concreta como por exemplo o mobiliário que faz parte do cotidiano das pessoas, e constrói obras abstratas, por vezes, imagens insólitas, inusitadas, que exigem que o leitor escave camadas de memória e afine sua percepção para decifrar o desvio poético e instaurar o sentido.

O tema é a violência a que a humanidade foi e ainda é submetida em todos os recantos do mundo, e em especial a América Latina nas histórias de opressão, ditaduras, guerras civis, direitos civis violados, etc.

\begin{abstract}
Mas minha obra não está baseada - nem é sua narrativa-, numa experiência direta; é antes memória da experiência. E como todos sabemos, todos temos má memória, a memória sempre está esvaindo, a memória sempre está desaparecendo. $\mathrm{O}$ que me interessa é a memória que está sempre nesse processo de esquecimento, e é aí que se inscreve minha obra. (SALCEDO, 2005, p.125)
\end{abstract}

Sua obra revela a memória como cicatriz ou como processo contínuo de cicatrização... Considerando que a cicatriz é uma marca que desvela a dor vivida, não é o apagamento, mas sim, é a marca ativadora da memória.

\section{CICATRICEMENT}

" una cicatriz que no se cierra: la cicatriz de nuestro tiempo"

Paul Celan

Em duas exposições recentes (2013), uma na Estação Pinacoteca, em São Paulo, e outra na Casa Daros, no Rio de Janeiro, nos deparamos com a obra artista colombiana Doris Salcedo, onde pudemos perceber algumas marcas autorais da artista como a utilização de móveis de madeira com aparente uso e portanto com vestígios de vivências e memórias, e também, o deslocamento poético do objeto para construir discursos que impactam nossa percepção e nos levam a perceber uma presença dada principalmente pela ausência e pelo silêncio.

$\mathrm{Na}$ Estação Pinacoteca percorremos uma grande sala com um conjunto de 120 esculturas, onde cada uma era

\footnotetext{
${ }^{1}$ Maria Luiza Calim de Carvalho Costa, Professora Doutora- Faculdade de Arquitetura Artes e Comunicação- Unesp- Universidade Estadual Paulista, Av. Luiz Edmundo Carrijo Coube, 14-01, 17043-00,SP, Brasil, marialuiza @ faac.unesp.br
} 
composta por duas mesas de madeira sobrepostas invertidas e entre os tampos uma camada de terra prensada.

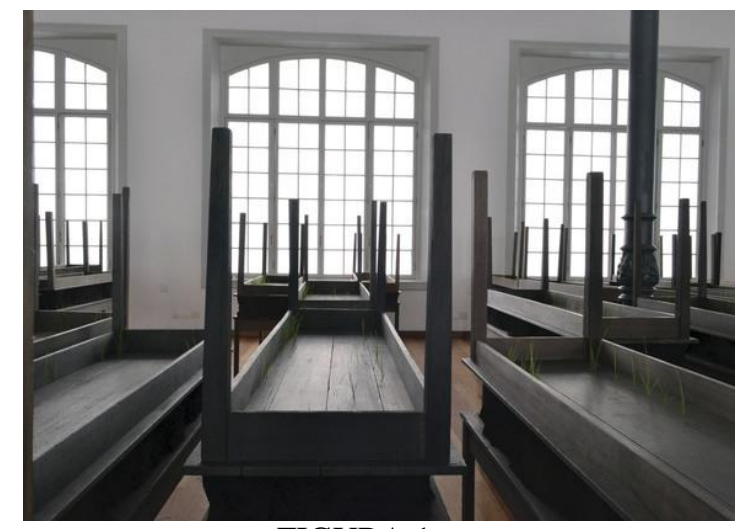

FIGURA 1

PLEGARIA MUDA, 2008-2010

DORIS SALCEDO (BOGOTÁ1958- )

ESTAÇÃO PINACOTECA- $8 / 12 / 2012$ A 15 /03/ 2013 SÃO PAULO

Ao caminhar pelo labirinto da instalação podíamos sentir o cheiro da terra prensada, observarmos as gramíneas brotando por entre os vãos - as fissuras da madeira - como vida que insiste em resistir... As mesas de madeira têm tamanho similar ao de um corpo humano que remete à idéia de que aquelas esculturas de mesas seriam sepulturas.

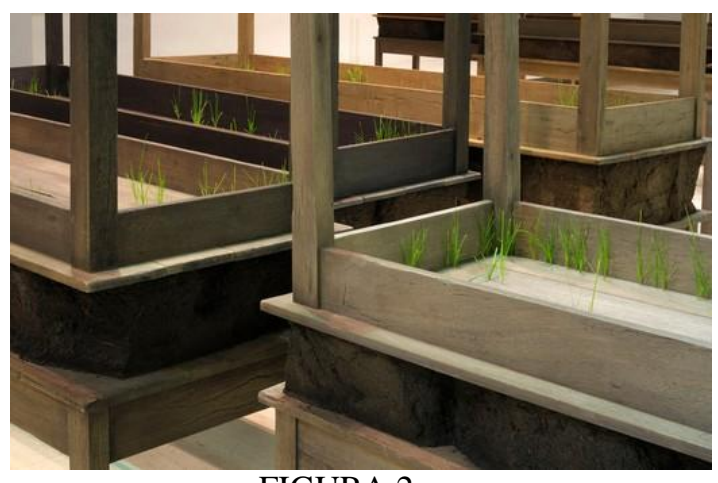

FIGURA 2

PLEGARIA MUDA, 2008-2010

DORIS SALCEDO (BOGOTÁ1958- )

ESTAÇÃO PINACOTECA- 8 /12 /2012 A 15 /03/ 2013 SÃO PAULO

Foi, para nós, uma sensação impactante... a instalação da artista colombiana imbricava-se com o espaço da exposição, com a história daquele espaço que foi sede do DEOPSDepartamento Estadual de Ordem Política e Social, entre 1940 a 1983, lugar de repressão, dos períodos mais violentos da história brasileira ( Estado Novo, 1937-1945, e a Ditadura Militar, 1964-1985) hoje espaço museólógico que abriga o "Memorial da Resistência".

O título da obra "Plegaria Muda" ancora o sentido da obra, há um silêncio, uma ausência sentida ao caminhar por entre essas esculturas sepulcrais : seriam todos os que desapareceram no processo histórico da Colômbia,e, de toda a América Latina...

Temos a madeira, a terra, a insistência de vida das plantas, a soma dessa aparente igualdade tão desigual que transforma centenas de identidades em anônimos, mas ao mesmo tempo impacta pela quantidade de exilados da história. Há odor. Madeira e terra. E há silêncio. O silêncio dos mortos, sua falta de voz, e também todos os silêncios políticos, estratégicos no ocultamento das verdades (Extraído do Folder "Para Saber Mais" oferecido por ocasião da exposição na Estação Pinacoteca, 2013, p.2).

$\mathrm{O}$ efeito de sentido da obra ecoou por muito tempo em nós, a experiência sinestésica de adentrar aquela grande sala silenciosa repleta de esculturas... aquele espaço fantasmagórico de vida e morte, memória e esquecimento, grito e silêncio.

Por ocasião do Simpósio sobre a situação social, política e artística na Colômbia, intitulado Guerra e Pá, realizado em Zurique em fevereiro de 2005, Doris Salcedo fala do silêncio em suas obras:

O silêncio é um momento importante quando estamos falando de violência política, porque um dos elementos que caracteriza a violência política é que ali a linguagem e a possibilidade de diálogo estão completamente excluídas (SALCEDO, 2005, p.130).

O silêncio trágico da vítima é para Salcedo "a forma mais eloquente de se dirigir a estes problemas" (Doris Salcedo, 2005, p.130).

A segunda exposição em que tivemos a oportunidade de conhecer, através da experiência da apreciação estética, a obra de Doris Salcedo ocorreu alguns meses depois em exposição intitulada "Cantos Cuentos Colombianos" na Casa Daros no Rio de Janeiro.

A Casa Daros abriu seu espaço ao público em março de 2013, após longo período de restauração e reforma do prédio que abriga exposições de um acervo de arte latinoamericana.

\begin{abstract}
A visão estrangeira que se tinha da arte latinoamericana era prejudicada pela ignorância e pela arrogância. Queríamos rebater essa percepção. Já em 2002 começamos apresentar a coleção em Zurique em exposições minuciosamente planejadas com esse intuito, acompanhadas de publicações cuidadosamente elaboradas (HERZOG, 2013, p.6).
\end{abstract}

Nessa exposição tivemos oportunidade de ver mais obras da artista executadas a partir de móveis. Objetos que resultam em imagens inusitadas, desconcertantes, enigmáticas... 
Vemos um móvel e sabemos que podemos usar, sentar. Queria transformá-los em objetos disfuncionais, e assim encontrar uma maneira de colocar todo sentido de uma obra na superfície, em uma superfície opaca e direta (SALCEDO, 2013, p.24).

Frente a uma obra como a da figura 3, onde um armário está preso, concretado, dentro de outro armário, nos faz construir percursos narrativos com o fim de encontrar um sentido para imagem tão desconcertante... Uma imobilidade, uma rigidez, uma impossibilidade são as sensações primeiras que nos assaltam... depois a idéia de o que está dentro do armário está escondido, então, um armário fixo pelo concreto é o que está encoberto por uma força que inviabiliza vislumbrar o que está dentro.

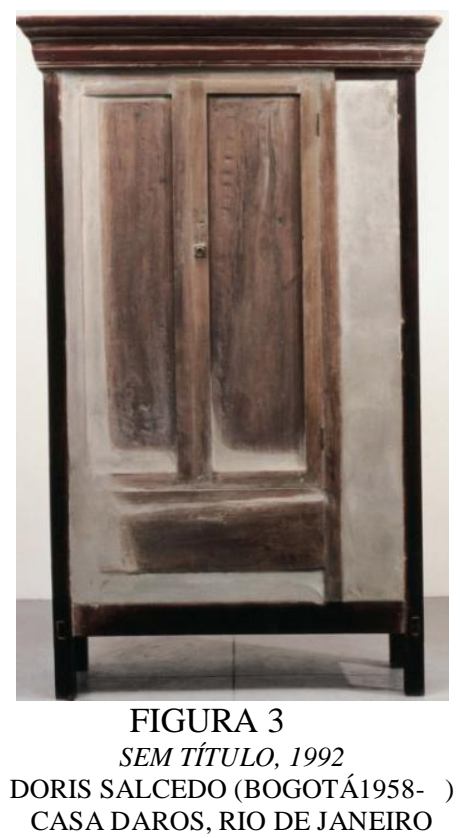

Outra obra (figura 4) que nos inquietou muito foi "6 de novembro". O objeto/escultura é composto por duas cadeiras colocadas em posição contrária, com formas que se entrecruzam, parece que estão unidas à força e que lutam para se libertarem... Há uma instabilidade de um lado, se olharmos para os pés das cadeiras, e por outro, uma solidez.

A obra tem a ver com a ideia de desorientação: quando acontece um episódio violento. Você fica completamente desorientado. [...] A forma é comum, conhecida, todos sabemos o que é uma cadeira; entretanto é monstruosa, volto à noção de criatura ou de inseto. Possui elementos antropomorfos, a escala... Todos os elementos são contraditos pela mesma peça... E é dessa forma que eu entendo a violência: não há possibilidade de se orientar (SALCEDO, 2013, p.30).

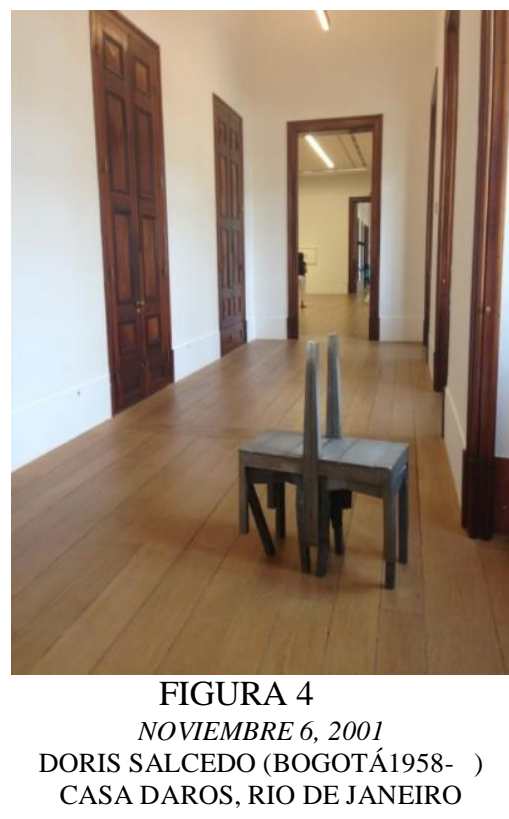

O título da obra NOVIEMBRE 6, oferece pistas ao leitor.

Remete à tragédia do Palácio da Justiça ocorrida em 6 e 7 de novembro de 1985.

Em 6 de novembro de 1985, um grupo pertencente à organização da esquerda armada que atuou na Colômbia nos anos 1970 e 1980 - M-19 - ocupou o Palácio da Justiça colombiano, em Bogotá, para pedir que o então presidente Belisário Betancur fosse julgado por crimes contra o povo colombiano.

O Exército invadiu o local com tanques blindados e bombas resultando em mais de cem mortos, entre eles magistrados e servidores e integrantes do M-19.

Em data muito recente, dia 11 de novembro de 2013, a Corte Interamericana de Direitos Humanos se instalou aqui no Brasil para sessão pública onde ouvirá testemunhas, peritos e envolvidos no massacre há 28 anos atrás, com o intuito de identificar os responsáveis pelo massacre e discutir reparação às famílias das vítimas, que vai desde o reconhecimento do erro pelo Estado até pagamento de indenizações ou realização de homenagens.

No processo, o Estado é acusado pela suposta tortura de inocentes como se fossem integrantes do M-19 e pelo desaparecimento de corpos. Alguns militares que atuaram no episódio chegaram a ser condenados na área penal, mas nunca houve um reconhecimento do Estado de responsabilidade no episódio.

Doris Salcedo realizou, em 2002, uma instalação/performance, intitulada NOVIEMBRE $6 \begin{array}{llll} & y & 7 & \end{array}$ utilizando as paredes do Palácio da Justiça, palco da tragédia colombiana.

Quando quis trabalhar o tema do Palácio da Justiça, tratei de conseguir objetos que tivessem sobrado desse evento trágico, mas não me foi permitido o 
acesso a nenhum desses objetos. Todos os objetos foram jogados fora, foram destruídos, vocês sabem. O edifício foi destruído. Então não há nada, não há lembrança. Como escultora, não havia nenhum rastro material que me permitisse reelaborar este acontecimento. O único que ficava era a data: 6 e 7 de novembro de 1985. Essa data eu creio que marca uma mudança na deterioração do conflito armado na Colômbia (SALCEDO, 2005, p.135-136).

Gradativamente, obedecendo aos horários dos acontecimentos trágicos, cadeira por cadeira começaram a cair de modo que ficaram penduradas na fachada do edifício. Em lentos ou rápidos movimentos, simultâneos ou não, as cadeiras silenciosamente deslizaram.

O tempo da obra performática durou o mesmo tempo dos acontecimentos de novembro1985.
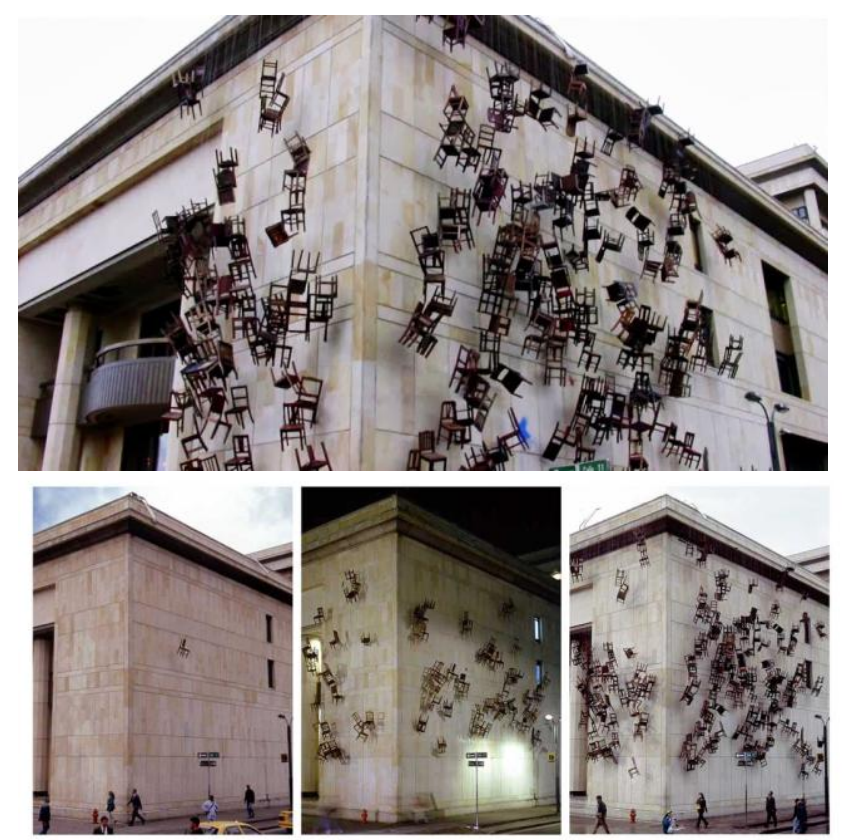

FIGURA 5

NOVIEMBRE 6 y 7,2002 DORIS SALCEDO (BOGOTÁ1958- ) PALÁCIO DA JUSTIÇA, BOGOTÁ

Queria trabalhar em torno do próprio edifício, in situ. A obra Noviembre 6 y 7 [...] Sobre os dois muros da fachada, deslizei cadeiras vazias, nos momentos em que, segundo os dados que tinha, as pessoas haviam morrido. Não avisei nem a imprensa, nem as pessoas, as cadeiras simplesmente começaram a cair (SALCEDO, 2013, p.28).

O centro de Bogotá, onde se situa o Palácio da Justiça passa a ser local de peregrinação durante a construção da instalação. Lugar contemplação e memória, narrativa reavivada a cada cadeira que deslizava e permanecia pendurada vazia...
Os transeuntes da cidade, à medida que contemplavam a transformação da paisagem urbana desvelavam a cicatriz daquele lugar. Cada cadeira se tornou uma marca ativadora da memória.

Doris Salcedo compõe obra em grande escala, enxertada no corpo da cidade, utilizando-se do silêncio, do tempo, do vazio para imitar o inimitável.

Em minha obra estou trabalhando permanentemente o irrepresentável, a ausência, o silêncio, o vazio, a morte. Por isso gosto muito de uma citação de Paul Valéry que diz que o que o artista faz é imitar, quase de maneira servil, aquilo que é inimitável na vida. è a imitação do inimitável. (SALCEDO, 2005, p.127).

Doris Salcedo com suas obras escava a memória encravada no ser, a dor concretada na alma, dá a ver o que está invisível, tange o intangível.

\section{REFERÊNCIAS}

[1] CANCLINI, Néstor García. Latino-americanos à procura de um Lugar neste Século. São Paulo: Iluminuras, 2008.

[2] GAY, José Maria Pérez. Paul Celan: Una cicatriz que no se cierra. In site Nexos virtual (www.nexos.com.mx) p. 2.

[3] LÓPEZ, Sebastian(moderador). Guerra e Pá: Simpósio sobre a situação social, política e artística na Colômbia (Zurich, 29 de janeiro 2005). Documentos Daros, Daros-Latinoamerica, 2005.

[4] HERZOG, Hanz-Michael.(org.) Cantos Cuentos Colombianos: arte contemporânea colombiana. Rio de Janeiro: Cobogó, 2013.

[5] SALCEDO, Doris. Conversa com Hanz-Michael Herzog (Bogotá6/2/2004).In HERZOG, Hanz-Michael.(org.) Cantos Cuentos Colombianos: arte contemporânea colombiana. Rio de Janeiro: Cobogó, 2013.

[6] SALCEDO, Doris. In LÓPEZ, Sebastian (moderador). Guerra e Pá: Simpósio sobre a situação social, política e artística na Colômbia (Zurich, 29 de janeiro 2005). Documentos Daros, Daros-Latinoamerica, 2005.

[7] PARA SABER MAIS. Doris Salcedo: Plegaria Muda. São Paulo Estação Pinacoteca, folder da exposição, 2013. 